\title{
Cournot vs. Bertrand under centralised bargaining ${ }^{\dagger}$
}

\author{
Debasmita Basak
}

Swansea University, UK

February 2017

\begin{abstract}
We revisit the debate on Cournot and Bertrand profit comparison in a vertically related upstream market for inputs. We find that when an input pricing contract is determined through centralised bargaining, the final goods producers earn higher (lower) profit under quantity competition than under price competition if the goods are substitutes (complements). Our results are strikingly different to the ones obtained from a similar comparison in other vertical pricing models.
\end{abstract}

Key Words: Bargaining; Bertrand; Cournot; Centralised bargaining; Vertical pricing; Welfare

JEL Classification: D43; L13; L14

Correspondence to: Debasmita Basak

Department of Economics, School of Management, Swansea University, Fabian Way, Swansea SA1 8EN, UK

Email: d.basak@swansea.ac.uk, Phone: +44 1792602075

\footnotetext{
$\dagger^{\dagger}$ I sincerely appreciate the comments received from the anonymous referee and the editor of this journal. I would also like to thank Arijit Mukherjee and Subhradeep De Sarkar for helpful discussions.
} 


\section{Introduction}

In a seminal paper, Singh and Vives (1984) show that firms' profits are higher (lower) under Cournot compared to Bertrand competition when the goods are substitutes (complements) and the input markets are competitive. However, it is often found that input suppliers and the final goods producers are involved in vertical pricing contracts. Considering the input suppliers as labour unions López and Naylor (2004) argue that the standard profit ranking shown in Singh and Vives (1984) is reversed when a monopoly input supplier and two final goods producers determine input prices through decentralised bargaining process and the input suppliers place sufficient weight on wage (input price) determination. Using a model of two-part tariff vertical pricing contract where the input supplier and the final goods producers involve in decentralised bargaining, Alipranti et al. (2014) further confirms the results of López and Naylor (2004). ${ }^{1}$

While the assumption of decentralised bargaining process is a useful starting point, it is equally intriguing to investigate whether the results alluded above hold when the input price contract constitutes centralised bargaining. The implication of centralised bargaining is justifiable in most continental European countries, such as Germany (Hirsch et al. (2014)). In the context of strategic input-price determination Calmfors and Driffill (1998), Danthine and Hunt (1994) argue that collective bargaining is more widely accepted as it internalises various negative externalities, such as unemployment. In light of this, we consider a model where the downstream firms involve in centralised bargaining with an upstream input supplier to determine the equilibrium input price. In contrast to the existing results on vertical pricing models, we show that the final goods producers earn a higher (lower) profit under Cournot structure than Bertrand when the goods are substitutes (complements) thus supporting the findings of Singh and Vives (1984).

\footnotetext{
${ }^{1}$ See López (2007), Mukherjee et al. (2012), Basak and Wang (2016) for related works on strategic input-price determination.
} 


\section{The model}

We consider an economy with two downstream firms, denoted by $D_{i}$ producing differentiated products where $i, j=1,2$ and $i \neq j$. The downstream firms require a critical input for production that they purchase from a monopoly input supplier, $U$ at a per unit price $w_{i}$ which is determined through generalised centralised Nash Bargaining. $U$ produces the inputs at a constant marginal cost of production, $c \in(0, a)$. We assume that one unit of input is required to produce one unit of the output, and $D_{i}$ and $D_{j}$ can convert the inputs to the final goods without incurring any further cost.

We develop a model of two stage game. At stage 1, $U$ involves in a centralised bargaining with a representative of $D_{1}$ and $D_{2}$ to determine the price of the critical input, $w_{i}$, $i=1,2$. At stage $2, D_{1}$ and $D_{2}$ compete either in quantities (Cournot competition) or in prices (Bertrand competition) and the profits are realised. We solve the game through backward induction.

\section{Equilibrium outcomes}

We assume that a representative consumer's utility function is given by

$$
V\left(q_{i}, q_{j}\right)=a \sum_{i} q_{i}-\frac{1}{2} \sum_{i} q_{i}^{2}-\gamma \sum_{i, i \neq j} q_{i} q_{j}+\zeta
$$

where $\zeta$ is the numeraire good and $q$ denotes the final good produced by the downstream firm. The parameter $\gamma \in(-1,1)$ measures the degree of product differentiation. If $\gamma>0$ the goods are substitutes and if $\gamma<0$ the goods are complements.

Using eq(1) we obtain downstreams' inverse and direct demand functions respectively

$$
P_{i}=a-q_{i}-\gamma q_{j} \quad \text { and } \quad q_{i}=\frac{a(1-\gamma)-P_{i}+\gamma P_{j}}{1-\gamma^{2}}
$$

Next, we derive the equilibrium outcomes contingent to the game structure discussed earlier. 


\subsection{Cournot competition}

We begin with the case where the downstream firms compete in quantities. Downstream firm's profit motive yields

$$
\operatorname{Max}_{q_{i}} \quad D \Pi_{i}^{C}=\left(a-q_{i}-\gamma q_{j}-w_{i}\right) q_{i}
$$

Solving the first order conditions we obtain the equilibrium output of the $i^{\text {th }}$ firm

$$
q_{i}^{C}=\frac{a(2-\gamma)-2 w_{i}+\gamma w_{j}}{1-\gamma^{2}}
$$

Given (3), the profit equation in (2) reduces to $D \Pi_{i}^{C}=\left(q_{i}^{C}\right)^{2}$.

Next we turn our analysis to stage 1 where the input prices are determined. To this extent we consider two types of price setting behaviour of the upstream firm - (i) uniform pricing and (ii) discriminatory pricing. In case of uniform pricing the upstream firm maximises $U \Pi^{C}=(w-c) \sum_{i} q_{i}$ with respect to $w$ whereas it maximises $U \Pi^{C}=$ $\sum_{i}\left(w_{i}-c\right) q_{i}$ with respect to $w_{i}$ if input pricing is discriminatory. Our modelling is similar to right-to-manage model. ${ }^{2} \mathrm{We}$ assume that the input price determination is an outcome of generalised Nash bargaining ${ }^{3}$ :

$$
w_{i}^{C}=\max \left[\left(U \Pi^{C}-\widehat{U \Pi}\right)^{\beta}\left(\sum_{i}\left(D \Pi_{i}^{C}-\widehat{D \Pi}\right)\right)^{1-\beta}\right]
$$

where $\widehat{U \Pi}$ and $\widehat{D \Pi}$ are the disagreement pay-offs of the upstream and downstream firms respectively. We assume that in the event of disagreement the downstream firms stop producing which entails zero reservation pay-offs for both input suppliers and final goods producers. The parameter $\beta$ (respectively $1-\beta$ ) measures the relative bargaining power of the input supplier (respectively final goods producers). A higher (lower) value of $\beta$

\footnotetext{
${ }^{2}$ The right-to-manage model has gained more popularity in the policy circle compared to efficient bargaining model. See Oswald (1993) and Layard (1991) who offered some arguments in favour of this issue.

${ }^{3}$ See Serrano (2008a, b) for a survey on Nash bargaining.
} 
corresponds to a higher (lower) bargaining power of the input supplier. At the extreme, if $\beta=1$, the input supplier has full bargaining power, and if $\beta=0$ the downstream firms have full bargaining power. We restrict our analysis to $\beta \in(0,1)$.

Maximising (4) we obtain the equilibrium input price as $w_{i}^{C}=\frac{1}{2}(a \beta-c \beta+2 c)$ both under uniform and discriminatory price setting. ${ }^{4}$

We derive the downstream and upstream profits as

$$
D \Pi_{i}^{C}=\left[\frac{(a-c)(2-\beta)}{2(2+\gamma)}\right]^{2} \quad \text { and } \quad U \Pi^{C}=\frac{\beta(a-c)^{2}(2-\beta)}{2(2+\gamma)}
$$

The consumer surplus and social welfare $(=C S+P S+U \Pi)$ are

and,

$$
\begin{gathered}
C S^{C}=\frac{(a-c)^{2}(2-\beta)^{2}(1+\gamma)}{4(2+\gamma)^{2}} \\
S W^{C}=\frac{(a-c)^{2}(2-\beta)(6+\beta+2 \gamma+\beta \gamma)}{4(2+\gamma)^{2}}
\end{gathered}
$$

\subsection{Bertrand competition}

Now, we consider the situation where the downstream firms compete in prices and repeat the same exercise as in section 3.1. Downstream firms maximise the following

$$
\operatorname{Max}_{P_{i}} \quad D \Pi_{i}^{B}=\left(P_{i}-w_{i}\right)\left(\frac{a(1-\gamma)-P_{i}+\gamma P_{j}}{1-\gamma^{2}}\right)
$$

The equilibrium price and output of the $i^{\text {th }}$ firm can be found as ${ }^{5}$

\footnotetext{
${ }^{4}$ In discriminatory input price setting, the negotiation between $U$ and the two downstream firms could be such that $U$ charges an exorbitantly high input price to one of the downstream firms that it becomes inactive and the other downstream firm produces like a monopolist. Straightforward calculations show that by charging $w^{C} \geq$ $\frac{a(4-2 \gamma+\beta \gamma)+c(2-\beta) \gamma}{4}$ and $w^{B} \geq \frac{a\left(4-2 \gamma+\beta \gamma-2 \gamma^{2}\right)+c(2-\beta) \gamma}{2\left(2-\gamma^{2}\right)}$ under Cournot and Bertrand competition respectively, $U$ can oust away one of the downstream firms and let the other downstream firm to produce like a monopolist. The upstream profit, in this situation, becomes $\frac{\beta(a-c)^{2}(2-\beta)}{8}$ which is lower than $U \Pi^{C}$ in eq(5) and $U \Pi^{B}$ in eq(9). As $U$ behaves opportunistically and always maximises its profit, our main focus remains on the duopoly case.
} 


$$
\begin{aligned}
& P_{i}^{B}=\frac{a(1-\gamma)(2+\gamma)+\left(2-\gamma^{2}\right) w_{i}+\gamma w_{j}}{4-\gamma^{2}} \\
& q_{i}^{B}=\frac{a(1-\gamma)(2+\gamma)-\left(2-\gamma^{2}\right) w_{i}+\gamma w_{j}}{\left(1-\gamma^{2}\right)\left(4-\gamma^{2}\right)}
\end{aligned}
$$

Given the above, downstream's profit maximisation problem in (7) reduces to $D \Pi_{i}^{B}=$ $\left(1-\gamma^{2}\right)\left(q_{i}^{B}\right)^{2}$

Substituting the equilibrium output levels and profit levels in (4) and differentiating the expression with respect to $w$ (in case of uniform pricing) and $w_{i}$ (in case of discriminatory pricing) we get the equilibrium input price as $w_{i}^{B}=\frac{1}{2}(a \beta-c \beta+2 c)$.

The net equilibrium profits of $D_{i}$ and $U$ are

$$
D \Pi_{i}^{B}=\frac{(a-c)^{2}(2-\beta)^{2}(1-\gamma)}{4(1+\gamma)(2-\gamma)^{2}} \quad \text { and } \quad U \Pi^{B}=\frac{\beta(a-c)^{2}(2-\beta)}{2(1+\gamma)(2-\gamma)}
$$

The consumer surplus and social welfare are

$$
\begin{gathered}
C S^{B}=\frac{(a-c)^{2}(2-\beta)^{2}}{4(1+\gamma)(2-\gamma)^{2}} \\
\text { and, } \quad S W^{B}=\frac{(a-c)^{2}(2-\beta)(6+\beta-4 \gamma)}{4(1+\gamma)(2-\gamma)^{2}}
\end{gathered}
$$

Corollary 1: The equilibrium input price under Bertrand competition is identical to that of

\section{Cournot competition.}

The rationale for this result follows from Dhillon and Petrakis (2000), who show that, if the input supplier's objective function is log-linear in input prices and if bargaining takes place over wages alone (also holds in our case), the equilibrium wage rate is

\footnotetext{
${ }^{5}$ It is noteworthy that if $\gamma$ is close to unity and $w_{1}<w_{2}$, then firm 1 may have an incentive charge $\left(w_{2}-\epsilon\right)$ where $\varepsilon>0$ and raise its profit while firm 2 sells nothing. Thus, there exists a unique equilibrium (albeit in a limiting sense) where firm 1 charges $P_{1}=\min \left(w_{2}, P^{M}\right)$ where the monopoly price $\left(P^{M}\right)$ is $\frac{a+w_{2}}{2}$ and we simply use $w_{2}$ in place of $\left(w_{2}-\varepsilon\right)$ while it is understood that firm 1 serves the entire market. As the firms are symmetric in nature, analogous argument holds for firm 2. In a more trivial case, where $w_{1}=w_{2}=w$, both firms will produce $\frac{a-w}{2}$ by pricing the marginal cost.
} 
independent of several market features, such as the number of firms, the degree of product differentiation and the intensity of market competition. The input supplier charges the same input price under Cournot and Bertrand competition, as its profit motive solely depends on the industry labour demand and hence, market output. Due to its monopoly nature, the upstream firm appropriates a larger profit via higher industry output that arises due to a rise in intensity of product market competition (see Proposition 1). Note that, the input price effect ${ }^{6}$ under decentralised bargaining discussed in López and Naylor (2004) disappears in our analysis.

\section{Results}

We summarise our main results in the following propositions.

Proposition 1: If $\gamma \neq 0$ the downstream firms earn higher (lower) profits under Cournot competition than under Bertrand competition when the goods are substitutes (complements) whereas the upstream profit is strictly higher under Bertrand competition.

Proof: See that $\Delta \Pi=D \Pi_{i}^{C}-D \Pi_{i}^{B}=\frac{\gamma^{3}(a-c)^{2}(2-\beta)^{2}}{2(1+\gamma)\left(4-\gamma^{2}\right)^{2}}$ where $\Delta \Pi>0$ for $\gamma \in(0,1)$ and $\Delta \Pi<0$ for $\gamma \in(-1,0)$. And, $U \Pi^{C}-U \Pi^{B}=-\frac{\beta \gamma^{2}(a-c)^{2}(2-\beta)}{2(1+\gamma)\left(4-\gamma^{2}\right)}<0$ for $\gamma \in(-1,1)$.

The input price (read as marginal cost) being identical under Cournot and Bertrand competition, the reasoning behind downstream firm's profit ordering in our analysis, is similar to that of Singh and Vives (1984), i.e., competition being less fierce under Cournot competition compared to Bertrand competition ${ }^{7}$, the former competition generates higher (lower) downstream profits when the goods are substitutes (complements).

\footnotetext{
${ }^{6}$ López and Naylor (2004) argue that the labour demand being less elastic under Cournot than under Bertrand competition, the firm-specific input suppliers charge a higher input price in the former case than the latter.

${ }^{7}$ Check that $P_{i}^{C}-P_{i}^{B}=\frac{\gamma^{2}(a-c)(2-\beta)}{2\left(4-\gamma^{2}\right)}>0$ and $q_{i}^{C}-q_{i}^{B}=-\frac{\gamma^{2}(a-c)(2-\beta)}{2\left(4-\gamma^{2}\right)(1+\gamma)}<0$.
} 
The upstream profit, on the other hand, depends on the market output. A higher output level under Bertrand competition offers greater opportunity to the upstream firm to extract rent. Hence, the input supplier reaps higher profit under Bertrand competition than under Cournot.

Proposition 2: If $\gamma \neq 0$ Bertrand competition yields higher consumer surplus and social welfare than Cournot competition.

Proof: Check that $C S^{C}-C S^{B}=\frac{\gamma^{2}(a-c)^{2}(2-\beta)^{2}\left(\gamma^{2}-2 \gamma-4\right)}{4\left(4-\gamma^{2}\right)^{2}(1+\gamma)}<0 \quad$ and $\quad S W^{C}-S W^{B}=$ $-\frac{\gamma^{2}(a-c)^{2}(2-\beta)\left(8+4 \beta-4 \gamma+2 \beta \gamma-2 \gamma^{2}-\beta \gamma^{2}\right)}{4\left(4-\gamma^{2}\right)^{2}(1+\gamma)}<0$.

As follows from Proposition 1, downstream firms charge a higher market price under Cournot than under Bertrand competition. This serves as a negative externality to the consumers and creates lower consumer surplus under the former competition.

Again, we find that the loss in upstream profit and consumer surplus under Cournot competition is so severe that it outweighs the gains from producers surplus when the goods are substitutes. The comparison is straightforward if the goods are complements. Hence, social welfare under Cournot competition is strictly lower than Bertrand competition as traditional in the literature.

Clearly, Proposition 1 and 2 collapse when $\gamma=0$ i.e., when the type of competition becomes irrelevant.

Allowing a centralised generalised Nash bargaining between the input supplier and the final goods producers, we show that the net profits of the final goods producers are higher (lower) under Cournot competition than under Bertrand competition when the goods are substitutes (complements). Our findings contradict the existing results in vertical pricing models. 


\section{References}

Alipranti, M., C. Milliou and E. Petrakis, 2014, 'Price vs. quantity competition in a vertically related market', Economics Letters, 124: 122-126.

Basak, D. and L.F.S. Wang, 2016, 'Endogenous choice of price or quantity contract \& the implications of two-part-tariff in a vertical structure', Economics Letters, 138: 53-56.

Calmfors, L. and Driffill, J. (1988), 'Bargaining structure, corporatism and macroeconomic performance', Economic Policy, 3: 13-61.

Danthine, J. and J. Hunt, 1994, 'Wage bargaining structure, employment and economic integration', Economic Journal, 104: 528-41.

Dhillon, A. and E. Petrakis, 2002, 'A generalized wage rigidity result', International Journal of Industrial organisation, 20: 285-311.

Hirsch, B., C. Merkl, S. Müller and C. Schnabel, 2014, 'Centralized vs. decentralized wage formation: The role of firms' production technology', IZA Discussion Paper no. 8242.

Layard, R., S. Nickell and R. Jackman, 1991, 'Unemployment, macroeconomic performance and the labour market', Oxford University Press, Oxford.

López, M.C., 2007, 'Price and quantity competition in a differentiated duopoly with upstream suppliers', Journal of Economics and Management Strategy, 16: 469-505.

López, M.C. and R.A. Naylor, 2004, 'The Cournot-Bertrand profit differential: a reversal result in a differentiated duopoly with wage bargaining', European Economic Review, 48: 681-696.

Mukherjee, A., U. Broll and S. Mukherjee, 2012, 'Bertrand versus Cournot competition in a vertical structure: a note', Manchester School, 80: 545-559. 
Oswald, A. J., 1993, 'Efficient contracts are on the labour demand curve: theory and facts', Labour Economics, 1: 85-113.

Serrano, R., 2008a, 'Bargaining', The New Palgrave Dictionary of Economics, (2nd edition), S. Durlauf and L. Blume (eds.), McMillan, London.

Serrano, R., 2008b, 'Nash Program', The New Palgrave Dictionary of Economics, (2nd edition), S. Durlauf and L. Blume (eds.), McMillan, London.

Singh, N. and X. Vives, 1984, 'Price and quantity competition in a differentiated duopoly', Rand Journal of Economics, 15: 546-554. 